\title{
Fuzzy Value Stream Map Analysis Technology in the Enterprise of Application Research

\author{
Di Liang ${ }^{1, a}$, Guizhi Sun ${ }^{1, b}$,Shuang Wu ${ }^{1, c}$
}

${ }^{1}$ School of Mechanical Engineering, Shenyang University, Shenyang, Liaoning Province, China

asydxld@163.com, bsungz1992@163.com, c445391942@qq.com

Keywords: Value stream map; Fuzzy triangular number ;Lean production

\begin{abstract}
This paper takes the plastic waterproof junction box production line as the object of study. It analyzed enterprise production status, and then drawn the fuzzy value stream status map by using the value stream map and the combination of fuzzy triangular number method. It improved these problems existed in the fuzzy value stream status map, such as that inventory was too much because of push production, production cycle and changeover time was too long. It drawn the improved fuzzy value stream map. It makes delivery time shortened, and processing efficiency increased.
\end{abstract}

\section{Introduction}

An enterprise products components and parts for the automotive, transportation and communication industry, the following calls it BM. The paper is studying in workshop 3, it products communication components, which is a kind of high performance plastic waterproof junction box. Push production leads to the main problems of the workshop, such as that inventory is too much, production cycle is too long, changeover time is too long, parts of station production is excess.

Fu yuan put forward that the value stream was the basic responsibility units in the lean production, and was an extension of the value chain in 2004[1]. In 2006, Shannon w. Anderson described each value activity in the value chain from the perspective of cost leadership and differentiation characteristics[2]. With the development of the value stream map technology, the application of value stream maps gradually combined with other areas[3]. An Xiaofeng and others built a model based on the knowledge flow of the supply chain theory, and analyzed and studied the factors related to knowledge flows in the enterprise[4]. In many fields of triangular fuzzy number applied more widely and frequently[5].

Combining with the enterprise practice, it finds out the problems existing in the production process through the analysis about the present situation of workshop 3 internal production process from the perspective of enterprise value stream. It improves the process by using lean tools. The delivery time, improve the machining efficiency, and value-added time effect are verified and compared.

\section{Enterprise status value stream analysis}

Value stream is all the process for all products through the basic production process, including value added and non-value added process. It studies he production status of the enterprise started from the value stream of product. It focuses on the enterprise overall production process.

The workshop 3 of BM products a variety of products of the same type. Through the survey of enterprise production data and field measurement, combining with the demand of customer data, it takes the type A waterproof box products as the object of study which demanding accounts for more than $95 \%$. Then the product for field data is collected and the value stream map is drawn, the present situation of 3 production workshop is analyzed overall.

In the process of gathering information, production network is drawn at the same time to record the production status.As shown in figure 1. 


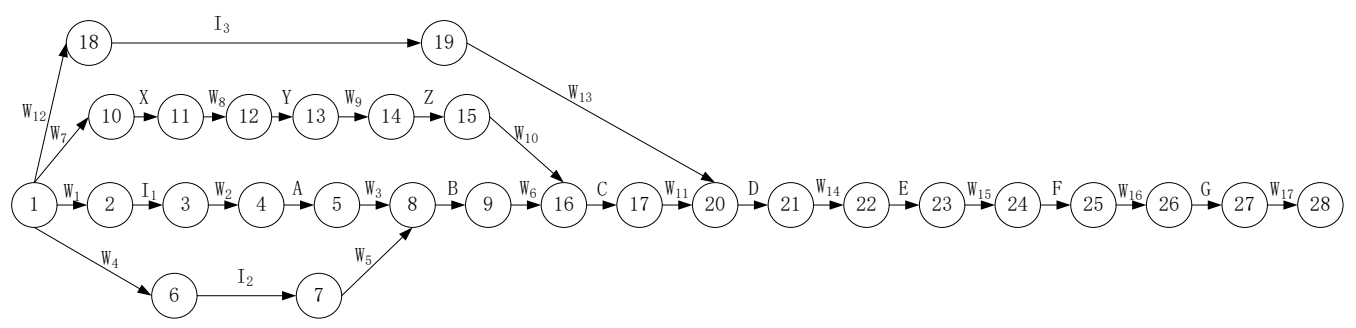

Fig. 1 Production activities network

Calculated, path 1 production lead time on the number of fuzzy time triangle as $\alpha=(15.9,27.5$, 15.9), the path 2 production lead time on the number of triangle fuzzy time for $\alpha=(14.9,27.5,14.9)$. Then compare the size of the two triangular fuzzy number. First the fuzzy mean and variance of path 1 and 2 are calculated separately:

$$
\begin{aligned}
& m\left(\alpha_{1}\right)=\frac{l+m+u}{3}=\frac{15.9+27.5+41.8}{3}=28.4 \\
& \sigma\left(\alpha_{1}\right)=\frac{l^{2}+m^{2}+u^{2}-l \times m-l \times u-m \times u}{18} \\
& =\frac{15.9^{2}+27.5^{2}+41.8^{2}-15.9 \times 27.5-15.9 \times 41.8-27.5 \times 41.8}{18}=28.052 \\
& m\left(\alpha_{2}\right)=\frac{l+m+u}{3}=\frac{14.9+27.5+42.9}{3}=28.43 \\
& \sigma\left(\alpha_{1}\right)=\frac{l^{2}+m^{2}+u^{2}-l \times m-l \times u-m \times u}{18} \\
& =\frac{14.9^{2}+27.5^{2}+42.9^{2}-14.9 \times 27.5-14.9 \times 42.9-27.5 \times 42.9}{18}=32.776
\end{aligned}
$$

According to the judgment standard, because the path to the average of 2 should be greater than the average of path 1 , so 2 is the critical path, the status of fuzzy stream value map of path 2 is drawn by using Visio, as shown in figure 2.

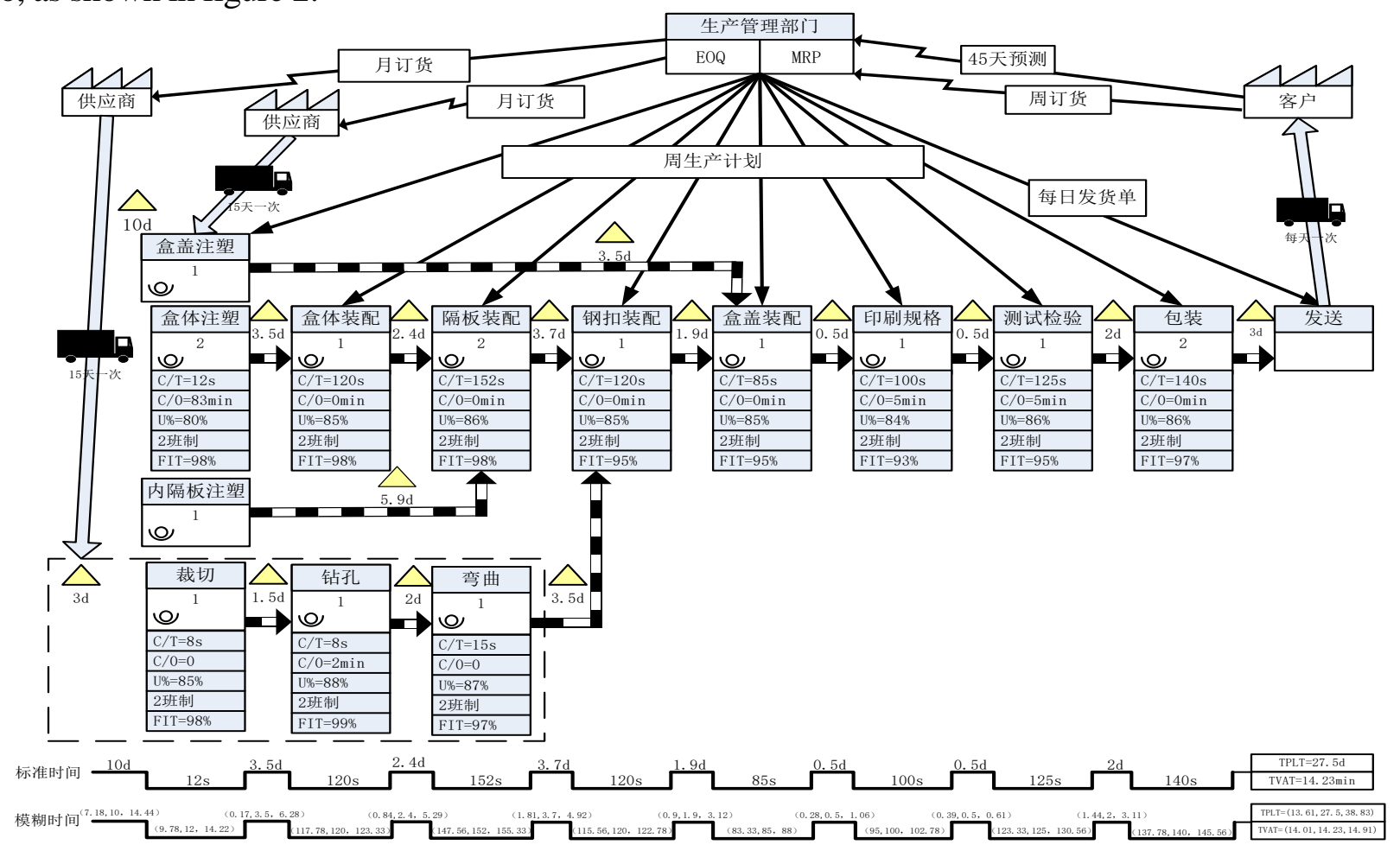

Fig. 2 The status value stream map

The status value stream map shows the workshop 3 current production status. It can be seen that there are six main problems existing in the workshop from the status value stream map: 
Push production caused by excessive inventory. From the status value stream map, we can see that workshop use the push production mode. Because the factory production status is not very stable, sometimes the injection molding equipment break down, so that assembly location can't product. But now box body forming and the manufacture of stainless steel continues to produce without knowing, then causing inventory accumulation.

Production cycle is too long because of long stock time. From the status value stream map, we can see that there are many inventory in the whole production process, and it has inventory almost between every two station. The inventory time of WIP is long, so that the production cycle is 28 days. Workshop completes a production plan for at least a month, the enterprise production flexibility is very low.

The changeover time is too long. Through the collection of each station data, it was found that the changeover time of molding injection molding is long, it is more than an hour, which causes a lot of waste.

Local production imbalance. Production line balancing is to get each station of production lines reasonable adjustment according to the beat, make it under the take time. Production line balancing can help enterprises use human resources reasonably, balance the workload, reduce waste and increase benefit of the enterprises. The diaphragm assembly and packaging production time go over $135 \mathrm{~s}$.

Part of the station excess production. The production of injection station and steel buckle processing station is very big from the status value stream map. Overproduction can cause the accumulation of inventory. It not only makes fund overstocking, but also makes the production not smooth.

Workshop layout is unreasonable, the logistics route is long. It is found that there are a lot of material flow between station and station, station and inventory by collecting information of scene and the status value stream map. It needs people to carry. A lot of logistics routes are crossing because of the workshop layout problem. And transportation distance and carrying amount is large.

\section{Production process improvement plan.}

The introduction of streamline production. The continuous flow is used the between box body assembly, diaphragm assembly, steel buckle assembly, lid assembly. Using the four major "ECRS" principles to analyze the four production workstation. It is found that the take time of workstation 2 is 152 $\mathrm{s}$, which beyond the take time, and a worker responsibly bore four hole on the box body.

U shaped production line design. In order to realize the flexible production, then designing a $U$ shaped production line layout at the same time. The improvement layout diagram is shown in figure 3.

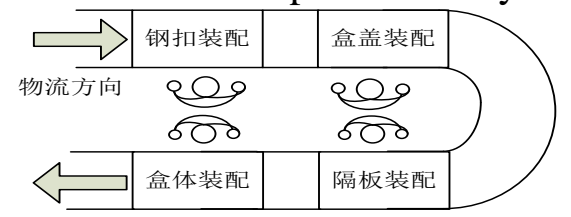

Fig. 3 The layout of $U$ shaped

Other production line should be use U shaped production line. And try to combine several different U shaped production line into a combination of production line to improve unreasonable layout, eventually forming the reasonable layout of the workshop.

Pull production mode is established. In the 3 workshop, production mode is a typical push production, then bring in pull production system in view of the current production status, so that can eliminate inventory waste between workstation. The Kanban is designed between workstation. Then the supermarket pull system is brought in.

The SMED(Single Minute Exchange of Die ) of injection workstation. Before the changeover operation is improved, first, you need to distinguish between internal and external work. Then transform some internal operation into external operation. Using "5W1H" and "ECRS" principles to improve in view of the unreasonable internal work of the process.

\section{The future value stream maps and analysis of improvement effect.}

The enterprise production process is improved according to the above lean method, workshop 3 value stream map is shown in figure 4. 


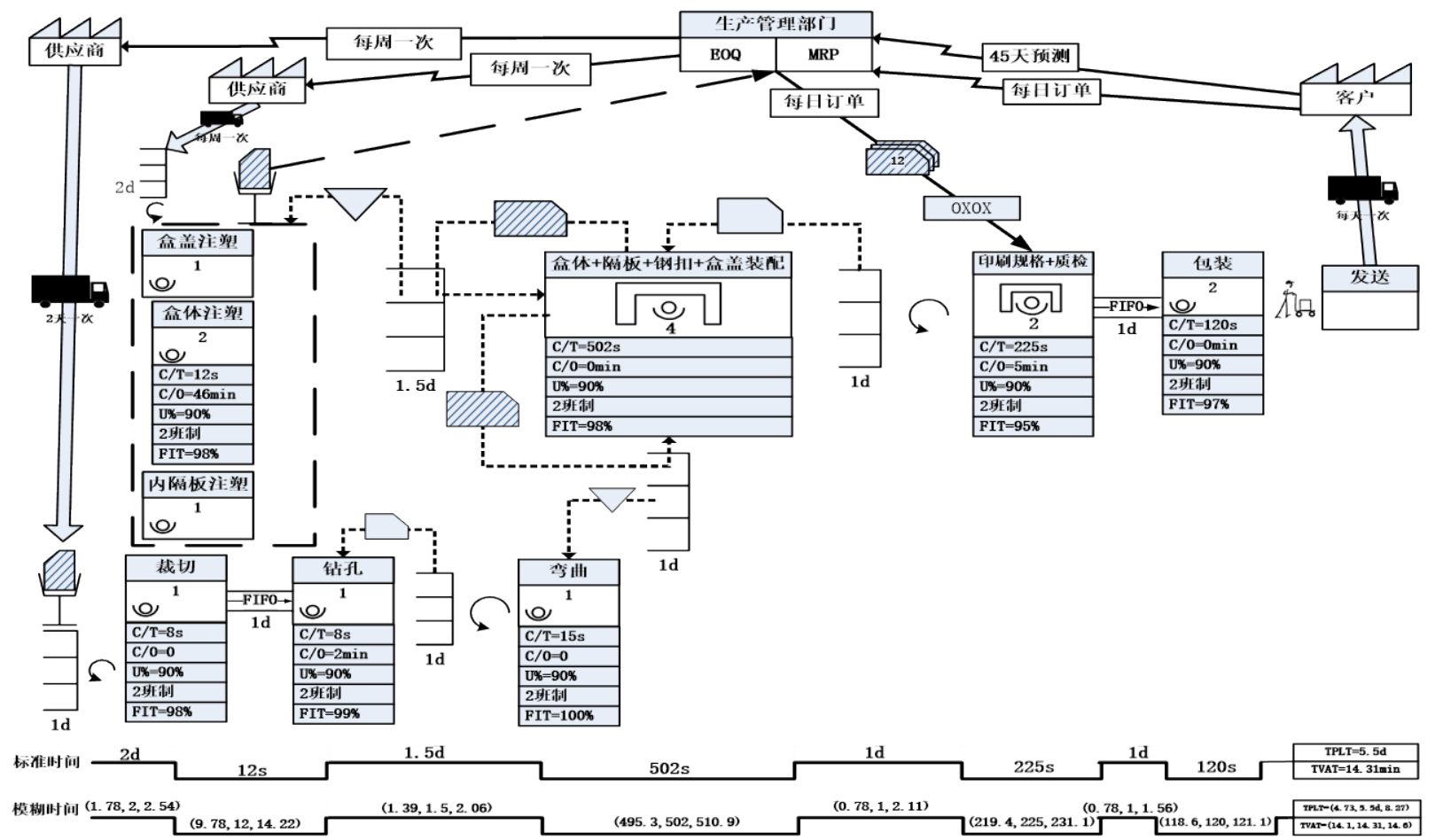

Fig. 4 The future value stream map

Summarize the results of before and after improvement based on the improved value stream map and the change of the production data, table 1 is shown.

Table 1 The comparison table of improvement results

\begin{tabular}{cccccc}
\hline project & delivery cycle $(\mathrm{d})$ & $\begin{array}{l}\text { value-creating } \\
\text { time }(\mathrm{min})\end{array}$ & $\begin{array}{l}\text { non value-creating } \\
\text { time }(\mathrm{d})\end{array}$ & staff $(\mathrm{m})$ & working efficiency \\
\hline before & 27.5 & 14.23 & 27.5 & 16 & $0.036 \%$ \\
after & 5.5 & 14.31 & 5.5 & 15 & $0.181 \%$ \\
rate & $80 \%$ & $1 \%$ & $80 \%$ & $6.25 \%$ & $402.78 \%$ \\
\hline
\end{tabular}

The data shows that the enterprise mode of production turn into pull production in the table. The process is optimized and improved, the delivery cycle is shorten,the machining efficiency is increased, the effect is very obvious.

\section{Conclusion}

Apply the value stream map, the fuzzy triangular number and lean conceptions to improve the production process, then analyze the workshop production process and investigate the production operation on site. It is found that the delivery period is shorten by $80 \%$, non value-added time is reduced by $80 \%$, the number of employee is decreased, machining efficiency is increased four times.

\section{References}

[1] Y.L. Fu: Accounting Research. Vol. 4 (2004), p. 28-34.(In Chines)

[2] S W, Anderson: Management Handbooks of Management Accounting Research.Vol. 11 (2006), p. 481-506.

[3] J P.Womack, D T.Jones: Lean Solutions (Detroit: Free Press, America 2005)

[4] X.F. An, X.M. Zhang, H.T. Zhang: Science and Technology Management Research. Vol. 2 (2009), p. 191-193.(In Chines)

[5] W.J. Li, K.L. Xu: Electrical Equipment.Vol. 3 (2009), p. 41-44.(In Chines) 